\section{Effect of Low Shrinkage Monomers on Physicochemical Properties of Dental Resin Composites}

Dayane Carvalho Ramos Salles de Oliveira1, Karla Rovaris², Viviane Hass 3 , Eduardo José Souza-Júnior ${ }^{1}$, Francisco Haiter-Netoㄹ, Mario Alexandre Coelho Sinhoreti ${ }^{1}$

\begin{abstract}
The aim of this study was to evaluate the effect of low shrinkage monomers on physicochemical properties of dental resin composites. Two low shrinkage resin composites: one with a crosslink branching monomer (Kalore, GC Corp) and a novel monomer (Venus Diamond, Heraeus Kulzer) were compared to a conventional resin composite formulation (Filtek Z250, 3M/ESPE). The volumetric shrinkage was evaluated by $\mu$ CT analysis $(n=5)$ and the physicochemical properties by degree of $\mathrm{C}=\mathrm{C}$ conversion (DC), flexural strength (FS) and Young's modulus (YM) $(n=10)$. All samples were light cured by a LED device (Radii, SDI) with $16 \mathrm{~J} / \mathrm{cm}^{2}$. The results were analysed by one-way ANOVA and Tukey test for multiple comparisons $(\alpha=0.05)$. No statistical difference was found between $\mu$ CT shrinkage values to Kalore (1.8\%) and Venus Diamond (1.7\%) ( $p \geq 0.05) ; Z 250$ presented statistical highest shrinkage value (2.0\%). Kalore presented higher statistical DC (60.8\%) than Venus Diamond (49.5\%) and Z250 (49.6\%). No statistical difference was found between FS or YM properties to Venus Diamond and Z250; Kalore presented statistical lowest FS and YM properties ( $p \geq 0.05$ ). Conclusion: Using novel monomers seem to reduce polymerization shrinkage without affecting the physicochemical properties evaluated of resin composites rather than using crosslink branching monomers.
\end{abstract}

\author{
'Department of Restorative \\ Dentistry, Dental Materials \\ Area, Piracicaba Dental School, \\ UNICAMP - Universidade Estadual \\ de Campinas, Piracicaba, SP, Brazil \\ ${ }^{2}$ Department of Dental Radiology, \\ Piracicaba Dental School, UNICAMP \\ - Universidade Estadual de \\ Campinas, Piracicaba, SP, Brazil \\ ${ }^{3}$ Department of Restorative Dentistry, \\ UPG - Universidade Estadual de Ponta \\ Grossa, Ponta Grossa, PR, Brazil
}

Correspondence: Dra. Dayane Carvalho Ramos Salles de Oliveira, Avenida Limeira, 901, Areião, 13414-903 Piracicaba, SP, Brasil. Tel: +55-19-98244-1777. e-mail: dayoli87@gmail.com

\section{Introduction}

Resin composites exhibit viscoelastic behavior and are transformed from a viscous plastic to a rigid elastic structure during polymerization (1). Adhesive bonding of composites to teeth results in contraction stresses, the magnitude of which is dependent upon several factors. Depending on the magnitude of contraction stress, the shrinkage forces during the polymerization of resin composites are partially transmitted to the tooth-restoration interface, possibility compromising marginal integrity and causing tooth sensitivity and possible replacement of direct restorations (2).

Most conventional composites shrink between $3 \%$ and $5 \%$ during polymerization; low shrinkage composites have volumetric shrinkage of less than 3\% (3). The shrinkage is caused by loss of volume (4) according to the conversion and the molecular weight of the monomers of resin composites (5). Manufacturers recommend high radiant exposure in order to enhance the degree of $\mathrm{C}=\mathrm{C}$ conversion and improve the physical-mechanical properties of resin composites. Unfortunately, the monomer conversion is proportionally associated with polymerization shrinkage $(6,7)$.

Commonly, the organic matrix of resin restorative materials is composed primarily of Bisphenol A glycidyl methacrylate (Bis-GMA, Mw = $512 \mathrm{~g} / \mathrm{mol}$ ). The high molecular weight, the presence of phenolic groups in its backbone and the strong intermolecular interactions given by hydroxyl groups result in a highly viscous material with lower degree of $\mathrm{C}=\mathrm{C}$ conversion (8) compared to other monomers (9). To increase monomer conversion and decrease the viscosity, composite formulations include one or more diluent monomers with lower viscosity, such as triethylene-glycol di-methacrylate (TEGDMA, $286 \mathrm{~g} / \mathrm{mol}$ ), urethane dimethacrylate (UDMA, $470 \mathrm{~g} / \mathrm{mol}$ ) or ethoxylated bis-phenol A methacrylate (Bis-EMA, $540 \mathrm{~g} / \mathrm{mol}$ ) (10).

Depending on the organic matrix composition and the filler percentage, shrinkage can be reduced, even as the degree of $\mathrm{C}=\mathrm{C}$ conversion and other physical-mechanical properties. The incorporation of diluent monomers allows increasing filler content enabling the maintenance of composite volume regardless the organic matrix composition. On the other hand, many manufacturers developed low shrinkage resin composites with high molecular weight monomers chemically modified in order to reduce shrinkage even more without affecting viscosity or monomer conversion (11).

Thus, the aim of this study was to evaluate the shrinkage of two low shrinkage resin composites, one with a crosslink branching monomer (Kalore, GC Corp) and another with a novel monomer (Venus Diamond, Heraeus Kulzer) 
compared to a conventional resin composite (Filtek Z250, $3 \mathrm{M} / \mathrm{ESPE})$, as also those physicochemical properties by degree of $\mathrm{C}=\mathrm{C}$ conversion, flexural strength and Young modulus evaluation. The hypotheses tested were: (i) Low shrinkage resin composites will promote similar degree of $\mathrm{C}=\mathrm{C}$ conversion and lower shrinkage compared to the conventional resin composite; (ii) Low shrinkage resin composites will promote similar flexural strength and Young's modulus compared to the conventional resin composite.

\section{Material and Methods}

\section{Resin Composites}

Table 1 shows two low shrinkage resin composites: one with a crosslink branching monomer, the DX-511, represented in Figure 1 (Kalore, GC Corp, Tokyo, Japan) and another with a novel monomer, the TCD-DI-HEA, represented in Figure 2 (Venus Diamond, Heraeus Kulzer, GmbH, Gemrnay) were compared with a conventional resin composite formulation (Filtek Z250; 3M/ESPE, St. Paul, Mn, USA).

\section{Light-Curing Unit (LCU)}

The output power (mW) of the LCU (Radii, SDI, Schaan, Liechtenstein) was measured with a pre-calibrated power meter (Ophir Optronics, Jerusalem, Israel). Thus, the irradiance $\left(\mathrm{mW} / \mathrm{cm}^{2}\right)$ was determined by dividing the output power by the irradiator tip area. The radiant exposure was standardized as $16 \mathrm{~J} / \mathrm{cm}^{2}$, so the activation mode would not influence on the results (12).

\section{Shrinkage Analysis by Microcomputed Tomography (SHR)}

To evaluate polymerization shrinkage (\%) of the composites, the specimens ( $7 \mathrm{~mm} \times 2 \mathrm{~mm} \times 1 \mathrm{~mm}, \mathrm{n}=5)$ were scanned using a micro-CT (SkyScan model 1174, Skyscan, Kontich, Belgium), operated under the following conditions: $50 \mathrm{kV}$ accelerating voltage; $800 \mu \mathrm{A}$ beam current; $1 \mathrm{~mm}$ Al filter; $11.6 \mu \mathrm{m}$ pixel size at $1024 \times 1024$ resolution; 360 rotation at 0.3 step and averaging by one frame, which resulted in a scan time of about one hour and twenty minutes. For each sample 1.200 raw data were recorded and, after reconstruction, 278 axial tomographic sections were obtained using the NRecon (SkyScan, Kontich, Belgium) software. Ring artifact correction and smoothing tools were used. The samples volume was calculated from images immediately before and after the polymerization by the CTAn (Skyscan) software, the second measurement of volume was calculated following the first set threshold.

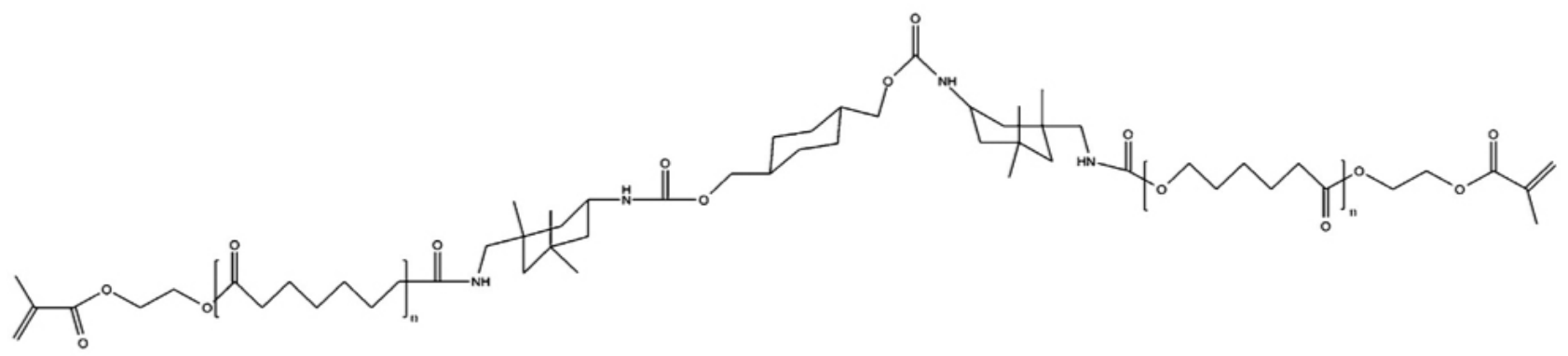

Figure 1. Crosslink branching monomer DX-511 (Kalore, GC Corp) chemical structure.

Table 1. Material, product, manufacturer, filler vol.\% and wt.\% and composition

\begin{tabular}{|c|c|c|c|c|}
\hline Material & Manufacturer & Filler (vol..\%) & Filler (wt.\%) & Composition \\
\hline $\begin{array}{l}\text { Filtek } \mathrm{Z} 250 \\
\text { (conventional } \\
\text { resin } \\
\text { composite) }\end{array}$ & $\begin{array}{l}\text { 3M/ESPE, } \\
\text { St Paul, } \\
\text { MN, USA }\end{array}$ & 68 & 82 & $\begin{array}{l}\text { 74-85 \% silane treated ceramic, } 1-10 \% \text { bisphenol a polyethylene glycol } \\
\text { diether dimethacrylate (BISEMA 6), } 1-10 \% \text { diurethane dimethacrylate, } \\
\text { 1-10\% bisphenol A diglycidyl ether dimethacrylate, }<5 \% \text { triethylene glycol } \\
\text { dimethacrylate, }<0.5 \text { benzotriadol, }<0.2 \text { ethyl 4-dimethyl aminobenzoate }\end{array}$ \\
\hline $\begin{array}{l}\text { Kalore } \\
\text { (low- } \\
\text { shrinkage resin } \\
\text { composite) }\end{array}$ & $\begin{array}{l}\text { GC Dental, } \\
\text { Bunkyo-Ku, } \\
\text { Tokyo, Japan }\end{array}$ & 69 & 82 & $\begin{array}{l}30-35 \% \text { filler (with lanthanoid fluoride), 20-33\% strontium/barium glass, } \\
20-30 \% \text { fluori-alumino-silicate glass, 5-10 \% urethane dimethacrylate, } \\
\text { 5-10\% urethane dimethacrylate (DX-511), 1-5\% dimethacrylate, } \\
1-5 \% \text { silicon dioxide, }<1 \% \text { photo-initiator, }<1 \% \text { pigment }\end{array}$ \\
\hline $\begin{array}{l}\text { Venus Diamond } \\
\text { (low- } \\
\text { shrinkage resin } \\
\text { composite) }\end{array}$ & $\begin{array}{l}\text { Heraeus } \\
\text { Kulzer, } \\
\text { Gmbh, } \\
\text { Germany }\end{array}$ & 64 & 81 & $\begin{array}{l}\text { 2-propenoic acid, 9octahydro-4,7-methano-1H-indene-5-diyl) } \\
\text { bis(methyleneiminocarbonyloxy-2,1-ethanediyl)ester, urethane } \\
\text { dimethacrylate, bis-(acryloyloxymethyl)tricycle-[5.2.1.02,6] decane (TCD- } \\
\text { Dl-HEA), (5 nm-20 nm) Ba-Al-F-Borosilicate glass, Si02 nanofiller }\end{array}$ \\
\hline
\end{tabular}




\section{Degree of $C=C$ Conversion $(D C)$}

The DC for each resin was measured using Fourier transform infrared spectroscopy (FTIR) (Spectrum 100, PerkinElmer, Waltham, MA, USA). The FTIR spectrophotometer was coupled to an attenuated total reflectance (ATR) attachment as previously described (13). Absorbance spectra included 16 scans at a resolution of 1 $\mathrm{cm}^{-1}$. Unpolymerized blends were scanned within a Teflon mold ( $7 \mathrm{~mm} \times 2 \mathrm{~mm} \times 1 \mathrm{~mm}$ thickness) placed on the ATR. The resin composites were photo-activated through a polyester strip with $16 \mathrm{~J} / \mathrm{cm}^{2}$ using a light-curing unit (Radii, SDI, Bayswater, Vic., Australia). The polymerized samples were scanned $48 \mathrm{~h}$ later, and unconverted carbon double bonds were quantified by calculating the ratio derived from the aliphatic $\mathrm{C}=\mathrm{C}$ (vinyl) absorption $\left(1638 \mathrm{~cm}^{-1}\right)$ to the aromatic $\mathrm{C}=\mathrm{C}$ absorption $\left(1608 \mathrm{~cm}^{-1}\right)$ signals for both polymerized and unpolymerized samples $(n=10)$. The $D C$ for each resin was calculated, according to the follow equation:

DC $(\%)=\{1-(\mathrm{Xa} / \mathrm{Ya}) /(\mathrm{Xb} / \mathrm{Yb})\} \times 100$,

in which, $X a$ (polymerized) and $X b$ (unpolymerized) represent the bands of the polymerizable aliphatic double bonds, and $\mathrm{Ya}$ (polymerized) and $\mathrm{Yb}$ (unpolymerized) represent the bands of an aromatic double bond (13).

Flexural Strength (FS) and Young's Modulus (YM)

The same specimens tested on DC were used to measure the FS and YM using a universal testing machine (model 4411; Instron, Canton, MA, USA) in a three-point bending design conducted at a crosshead speed of $0.5 \mathrm{~mm} / \mathrm{s}$ and span between supports of $6.0 \mathrm{~mm}$ until failure.

\section{Statistical Analysis}

For multiple comparisons, one-way ANOVA followed by Tukey's test was applied $(p=0.05)$ for the statistical analysis

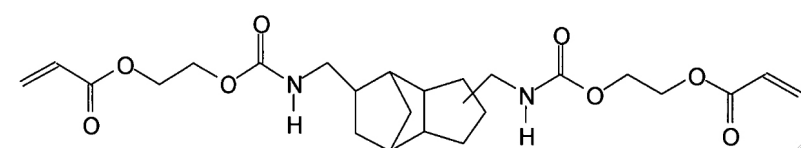

Figure 2. Novel monomer TCD-DI-HEA (Venus Diamond, Heraeus Kulzer) chemical structure.

Table 2. For each resin composite, the mean degree of $\mathrm{C}=\mathrm{C}$ conversion (DC) $(\%)$, shrinkage (SHR) (\%), flexural strength (FS) (MPa) and Young modulus (YM) (GPa) values \pm standard deviation are provided

\begin{tabular}{lcccc}
\hline Composites & DC (\%) & SHR (\%) & FS (MPa) & YM (GPa) \\
\hline Kalore & $68.82(2.1) \mathrm{A}$ & $1.84(0.1) \mathrm{B}$ & $81.68(7.6) \mathrm{B}$ & $2.60(0.4) \mathrm{B}$ \\
Filtek Z250 & $49.64(2.8) \mathrm{B}$ & $2.02(0.3) \mathrm{A}$ & $151.07(25.6) \mathrm{A}$ & $5.41(0.8) \mathrm{A}$ \\
Venus & $49.53(0.9) \mathrm{B}$ & $1.71(0.3) \mathrm{B}$ & $154.43(22.2) \mathrm{A}$ & $5.44(1.1) \mathrm{A}$ \\
\hline
\end{tabular}

Means followed by different letters in the same column are significantly different $(\mathrm{p}<0.05)$. of DC, FS, YM and SHR values.

\section{Results}

Table 2 shows the mean DC, SHR, FS and YM values \pm standard deviation for each of the resin composites evaluated.

No statistically significant difference was found between $\mu \mathrm{CT}$ shrinkage values to Kalore $(1.8 \%)$ and Venus Diamond (1.7\%); Z250 presented statistical higher shrinkage (2.0\%). Kalore presented statistical higher DC (60.8\%) than Venus Diamond (49.5\%) and Z250 (49.6\%). No statistical difference was found between FS or YM properties to Venus Diamond and Z250; Kalore presented statistical lower FS and YM properties.

\section{Discussion}

The first tested hypothesis that low shrinkage resin composites would promote similar degree of $\mathrm{C}=\mathrm{C}$ conversion and lower shrinkage compared to the conventional resin composite formulation was rejected. Kalore and Venus Diamond presented lower shrinkage (\%) compared to Z250 as previous observed in Table 2. Still, Kalore presented higher DC than Venus Diamond and Z250.

As expected, the shrinkage percentage of low shrinkage resin composites was reduced in comparison to the conventional resin composite. All methacrylatebased resins shrink to some extent, and contraction can be reduced by using monomers with a high molecular weight (14). In fact viscosity is an indicator of the ability of molecules to flow and a high viscosity value is indicative of the presence of intermolecular interactions that may account for the decreased flexibility of the corresponding polymeric network (9). Bis-EMA is a viscous monomer structurally similar to Bis-GMA, but without the two pendant hydroxyl groups, which participate in hydrogen bonding and are responsible for the extremely high viscosity of Bis-GMA. UDMA is more viscous than TEGDMA and Bis$E M A$, due to the hydrogen bonding between the NH and CO groups, however, it is less viscous than Bis-GMA, since amino groups form weaker hydrogen bonds compared to hydroxyl groups, and the Young modulus of the dimethacrylate polymers follows the increasing sequence:TEGDMA<Bis-GMA < UDMA<Bis-GMA (9). Thus, the presence of Bis-GMA may contribute to the high polymerization shrinkage values recorded with Filtek Z250 (15).

As the resin composites have similar filler volume content, is possible to conclude that the high molecular weight monomers in Kalore and Venus Diamond composition enabled the maintenance of composite volume, regardless the degree of $\mathrm{C}=\mathrm{C}$ conversion (11). Venus Diamond contains a novel 
monomer, the bis-(acryloyloxymethyl)tricycle-[5.2.1.02,6] decane - TCD-DI-HEA (Fig. 2) that is said to combine low shrinkage with low viscosity(15), once it has three connected rings in its structure (Fig. 2), that may induce the slow curing (16).. Kalore contains the DX-511 monomer from Dupont (Fig. 1), a high molecular weight monomer based on a urethane dimethacrylate, which leads to shrinkage reduction due to the low reactive group concentration available for reaction (15).

The basis for the lower level of contraction demonstrated by Kalore in the present study is the high molecular mass of the base monomer within Kalore, DX-511 (17). The molecular mass of DX-511 is about twice that of Bis-GMA and UDMA enabling DX-511 to exhibit a lower comparative density of reactive sites per unit of mass. As a result, when comparing specimens of equal mass, Kalore undergoes to lower volume shrinkage during polymerization compared to the conventional methacrylate based composites (18).

As low molecular weight monomers, crosslink branching monomers can indeed increase the degree of $\mathrm{C}=\mathrm{C}$ conversion and further decrease polymerization shrinkage $(6,7,10)$. That can explain the high monomer conversion of Kalore compared to the other resin composites evaluated. The addition of high molecular weight monomers with amount of crosslink branching enabled high monomer conversion while low polymerization shrinkage, as showed in Table 2.

Lower monomer conversion besides crosslink bonding can influence on the physical-mechanical properties of low-shrinkage resin composite, regardless the degree of $\mathrm{C}=\mathrm{C}$ conversion (19). Thus, the second hypothesis that low shrinkage resin composites would promote similar physicalmechanical properties compared to the conventional resin composite was rejected once Kalore presented lower physical-mechanical properties values compared to Z250 and Venus Diamond (Table 2) besides no statistical difference was found between physical-mechanical properties to Venus Diamond and Z250 ( $p \geq 0.05)$.

As observed in this study, Kalore presented the highest monomer conversion and lowest polymerization shrinkage; still, lowest physical-mechanical properties despite the addition of high molecular weight monomers with amount of crosslink branching, different from Venus Diamond, which the lower shrinkage than the conventional resin composite, moreover not compromising its physicalmechanical properties evaluated on this study. Thus, the materials composition appears to be the most important factor that interfere on composite polymerization shrinkage (20). On the other hand, despite shrinkage usually leads to a lower stress values (21), it does not necessarily reduce shrinkage stress effects in restored teeth (22). Thus, further studies should evaluated if the different modified monomers added into commercial low shrinkage composite really reduces shrinkage stress.

Within the limitations imposed by the experimental design used in the current study, the following conclusion can be drawn: using novel monomers seem to reduce polymerization shrinkage without affecting the physicochemical properties of resin composites rather than using crosslink branching monomers.

\section{Resumo}

0 objetivo deste trabalho foi avaliar o efeito de monômeros de baixa contração de polimerização nas propriedades físico-quimicas de resinas compostas. Duas resinas de baixa contração de polimerização, com monômeros do tipo crosslink (Kalore, GC Corp) ou do tipo novelar (Venus Diamond, Heraeus Kulzer) foram comparadas a uma resina composta convencional (Filtek Z250, 3M/ESPE) A contração de polimerização foi avaliada através da análise por $\mu \mathrm{CT}(n=5)$ e as propriedades fisicoquímicas através da análise do grau de conversão $C=C(G C)$, resistência flexural (RF) e módulo de Young (MY) $(n=10)$. Todas as amostras foram fotoativadas com uma fonte de LED (Radii, SDI) com $16 \mathrm{~J} / \mathrm{cm}^{2}$. Todos os resultados foram submetidos aos testes de análise de variância de 1 fator e ao teste de Tukey para comparações múltiplas $(\alpha=0,05)$. Nenhuma diferença estatística foi encontrada para os valores de contração de polimerização para Kalore $(1,8 \%)$ e Venus Diamond $(1,7 \%)(p \geq 0,05)$. Z250 apresentou estatisticamente maior contração de polimerização $(2,0 \%)$. Kalore apresentou estatisticamente maior GC $(60,8 \%)$ que Venus Diamond $(49,5 \%)$ e Z250 (49,6\%). Nenhuma diferença estatística foi encontrada para as propriedades RF e MY entre Venus Diamond e Z250. Kalore apresentou os menores valores estatisticos para FS e MY $(p \geq 0,05)$. 0 monômero novelar parece reduzir a contração de polimerização sem afetar as propriedades físico-químicas avaliadas das resinas compostas de forma mais adequada que a utilização de monômeros do tipo crosslinker.

\section{References}

1. Papadogiannis D, Kakaboura A, Palaghias G, Eliades G. Setting characteristics and cavity adaptation of low-shrinking resin composites. Dent Mater 2009;25:1509-1516.

2. Hilton TJ. Can modern restorative procedures and materials reliably seal cavities? In vitro investigations. Part 1. Am J Dent 2002;15:198-210.

3. Duarte S, Phark, JH, Varjao FM, Sadan A. Nanoleakage, ultramorphological characteristics, and microtensile bond strengths of a new low shrinkage composite to dentin after artificial aging. Dent Mater 2009;25:589-600.

4. Sakaguchi RL, Wiltbank BD, Shah NC. Critical configuration analysis of four methods for measuring polymerization shrinkage strain of composites. Dent Mater 2004;20:388-396.

5. Caughman WF, Rueggeberg FA. Shedding new light on composite polymerization. Oper Dent 2002;27:636-638.

6. Asmussen $E_{1}$ Peutzfeldt A. Influence of composition on rate of polymerization contraction of light-curing resin composites. Acta Odontol Scand 2002;60:146-154.

7. Davidson $\mathrm{CL}$, De Gee AJ. Light-curing units, polymerization, and clinical implications. J Adhes Dent 2000;2:167-173.

8. Floyd C, Dickens S. Network structure of Bis-GMA and UDMA-based resins systems. Dent Mater 2006;22:1143-1149.

9. Sideridou I, Tserki V, Papanastasiou G. Effect of chemical structure on degree of conversion in light-cured dimethacrylate-based dental resins. Biomaterials 2002;23:1819-1829.

10. Pfeifer C, Silva L, Kawano Y, Braga R. Bis-GMA co-polymerizations: Influence on conversion, flexural properties, fracture toughness and susceptibility to ethanol degradation of experimental composites. Dent Mater 2009;25:1136-1141.

11. Tessore G, Trinchero A. Post-operative sensitivity consequent to composite restorations in posterior sectors. Atti Italy Probagonsti in 
Odontoiatria 2001:62-65.

12. Ishikiriama SK, Maenosono RM, Oda DF, Ordonez-Agulhera JF, Wang L, Mondelli RFL. Influence of volume and activation mode on polymerization shrinkage forces of resin cements. Braz Dent J 2013;24:326-329.

13. Atai M, Watts DC. A new kinetic model for the photopolymerization shrinkage-strain of dental composites and resin-monomers. Dent Mater 2006;22:785-791.

14. Yap AU, Soh MS. Post-gel polymerization contraction of "low shrinkage" composite restoratives. Oper Dent 2004;29:182-187.

15. Marchesi G, Breschi L, Antoniolli F, Di Lenarda R, Ferracane J, Cadenaro M. Contraction stress of low-shrinkage composite materials assessed with different testing systems. Dent Mater 2010;26:947-953.

16. Boaro LC, Gonçalves F, Guimarães TC, Ferracane JL, Pfeifer CS, Braga RR. Sorption, solubility, shrinkage and mechanical properties of "lowshrinkage" commercial resin composites. Dent Mater 2013;29:398-404.

17. Dopheide $B$, Heiss M, Lee R, Reinfields K. Kalore technical manual. GC Co.; 2010.
18. Naoum SJ, Ellakwa A, Morgan L, White K, Martin FE, Lee IB. Polymerization profile analysis of resin composite dental restorative in real time. J Dent 2012;40:64-70.

19. Gajewski VES, Pfeifer CS, Fróes-Salgado NRG, Boaro LCC, Braga RR. Monomers used in resin composites: degree of conversion, mechanical properties and water sorption/solubility. Braz Dent J 2012;23:508-514.

20. Pires-de-Souza FCP, Drubi-Filho B, Casemiro LA, Garcia LFR, Consani S. Polymerization shrinkage stress of composites photoactivated by different light sources. Braz Dent J 2009;20:319-324.

21. Gonçalves F, Pfeifer CS, Meira JB, Ballester RY, Lima RG, Braga RR. Polymerization stress of resin composites as a function of system compliance. Dent Mater 2008;24:645-652.

22. Tantbirojn D, Pfeifer CS, Braga RR, Versluis A. Do low-shrink composites reduce polymerization shrinkage effects? J Dent Res 2011;90:596-602.

Received July 30, 2014 Accepted February 10, 2015 